\title{
A Study of the Focus Expression Function of the Modal Adverb "yòu" in Modern Chinese
}

\author{
Shuang Dai ${ }^{1, a}$ and Chunhong $\mathrm{Qi}^{1, \mathrm{~b}^{*}}$ \\ ${ }^{1}$ Yunnan Chinese Language and Culture College, Yunnan Normal University, Kunming, Yunnan, \\ 650092, China \\ a $961381620 @ q q . c o m,{ }^{b} 810982089 @ q q . c o m$.
}

Keywords: yòu; Focus; Accent; High Line; Low Line; Voice Length

\begin{abstract}
The main point of view in the academia is that "yòu" is generally lightly read when expressing refutation and negative tone adverbs with a focus. This paper uses experimental phonetics to test 10 subjects "wǒ yòu méi huā nǐ de qián, guăn nà me duō!", "nǐ zěn me yòu lái le ?" The pitch frequency percentage values of each of the two sentences were analyzed, pointing out that "yòu" tends to be the focus in negation, rebuttal tone or rhetorical tone. When "yòu" is the focus, its pragmatic function is to serve as the narrow focus of the whole sentence to accentuate the pragmatic function of negative presupposition and counter-question. The paper also proves that with the semantic blur of "yòu", its tendency to focus is smaller.
\end{abstract}

\section{Introduction}

When "yòu"is a modal adverb, its explanation in "Eight Hundred Words in Modern Chinese" is: 1. It indicates a turning point; 2. It is used to strengthen the negation; 3 . It is used to strengthen thequestion.[1]Halliday (1967) believes that the focus is on the most prominent part of tonal stress, which means that the focus must be accented in the sentence.[2]Wang Li (1946) believed that the tone adverb "yòu" means a resolutely negative tone, and the word "yòu" with a frustrating tone is a heavy tone.[3]Lu Shuxiang (1984: 104) pointed out that "zhè yī huí nǐ yòu shì tóu yī gè." can be read lightly or reread in the "yòu". In "bié wèn wǒ, wǒ yòu bù shì tóu yī gè.", "yòu" must be read lightly.The first "yòu" is a frequency adverb, and the second "yòu" is a modal adverb. That is to say, he thinks that "yòu"must be lightly read when he is a modal adverb. "yòu" must not be the focus.[4]Shi Jinsheng (2005:53) believes that "yòu" expresses a kind of refuting tone when acting as a modal adverb, its main role is to highlight, after "yòu" is the component that needs to be highlighted, and "yòu" can be regarded as the focus operator. This time, "yòu" is read lightly.[5]Li Jun and Yin Shulin (2008: 119) generalized the usage of the modal adverb "yòu" to highlight the opposite relationship, thus strengthening the results. And "yòu" is generally read lightly in spoken language, which is considered to be one of the manifestations of the use of "yò" in tone usage different from other usages. They also think that the tone adverb "yòu" is to read lightly without being a focus.[6]Summarizing the previous studies, we can find that scholars think that when they are "repeated" in the modal adverbs, the modal adverb "yòu" will not focus.

This paper will analyze the sentence with the negative tone "wǒ yòu méi huā nǐ de qián, guăn nà me duō!" and the sentence with the rhetoric "nǐ zěn me yòu lái le ?". The "yòu" in the first sentence is "yòu1" and the second sentence is "yòu2". The method of experimental linguistics is used to test whether the modal adverb "yòu" serves as the focus of the sentence in the negative tone and the rhetorical tone. "yòu1" and "yòu2"are different when focusing.

\section{Description of the Experiment}

We selected 10 students aged 18 to 28 in the first and second grades of Yunnan Normal University and graduate students in the first and second grades, including 5 female students and 5 male students. Their Mandarin level is $2 \mathrm{~A}$ and above. During the experiment, please read "wǒ yòu méi huā nǐ de qián, guăn nà me duō!" and "nǐ zěn me yòu lái le ?" in Mandarin. Don’t tell them the 
purpose of reading before reading.Recording situation is as follows: recording and segmentation software are: Praat5.22, sampling rate is $11025 \mathrm{HZ}$, 16-bit, mono; students are required to read 3 times per sentence, sentence and sentence interval 4 seconds, natural state, uniform pronunciation.

\section{Analysis of Focuses in the Sentences with "yòu1" and "yòu2"}

Analysis of Experimental Language Map. In the analysis, we first use the minispeechlab software developed by Nankai University to press the rhythm words "wǒ", "yòu", "méi", "huā nǐ de qián", "nǐ ", " zěn me", "yòu", " lái le " The frequency value of each word is analyzed.In order to reduce the difference in individual pronunciation, use the formula: $\mathrm{St}=12 * \lg (\mathrm{f} / \mathrm{fr}) / \lg 2$ (" $\mathrm{f}$ " indicates the Hertz value to be converted, "fr" indicates the reference frequency, male is set to $55 \mathrm{~Hz}$, and the female is set to $64 \mathrm{~Hz}$ ). Convert the frequency value to a semitone value in the logarithmic domain. Then use the formula $\mathrm{Ki}=100 *(\mathrm{Gi}-\mathrm{Smin}) /(\mathrm{Smax}-\mathrm{Smin})$ (where Smax is the upper semitone value of the entire sentence domain, and Smin is the lower semitone value of the sentence domain) to calculate 9 points per word (minispeechlab software). Take the percentage value on the pitch data at 9 points of each word, find the maximum and minimum values, and make a percentage span of each of the 10 experimental sentences.

Through the analysis of the percentage span map, it can be concluded that there are 7 cases of "yòu1" focus, and the situation of the language map is similar to that of Figure 1. There are 3 cases of the prosodic word "huā nǐ de qián" as the focus. 2, 3, 4. There are 9 cases in which "yòu2" is the focus, and the situation of the language map is similar to that in Figure 5. There is one case where the prosodic word "zěn me" is the focus, as shown in Figure 6.

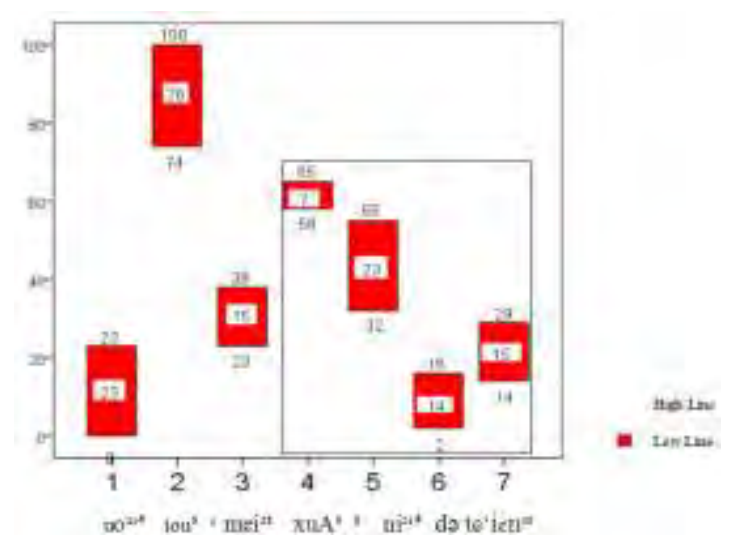

Figure 1. Yang Qianwei “yòu1” sentence percentage chart

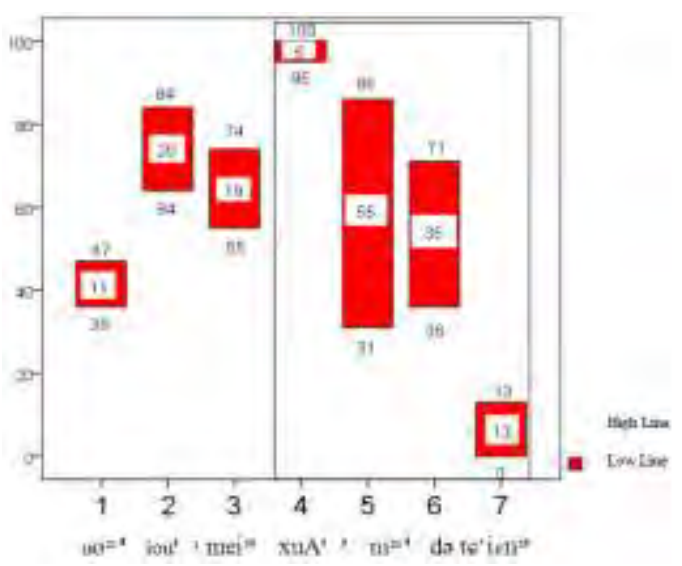

Figure 3. Liu Rui "yòu 1" sentence percentage chart

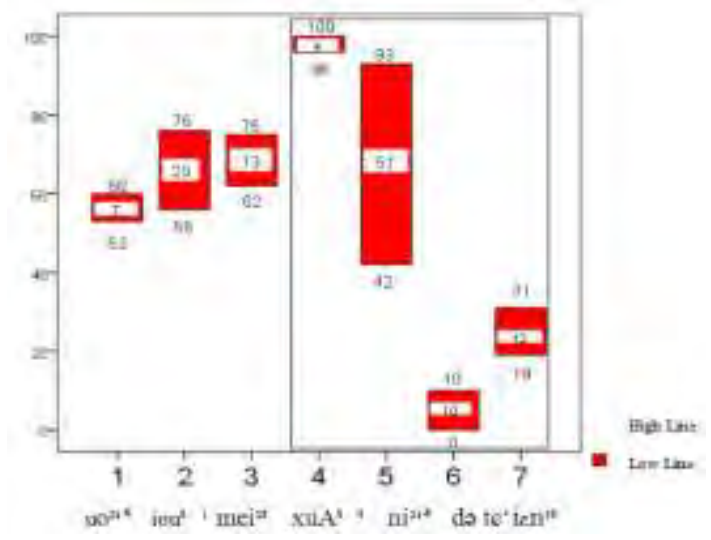

Figure 2. Zhao Haiting "yòu1" sentence percentage chart

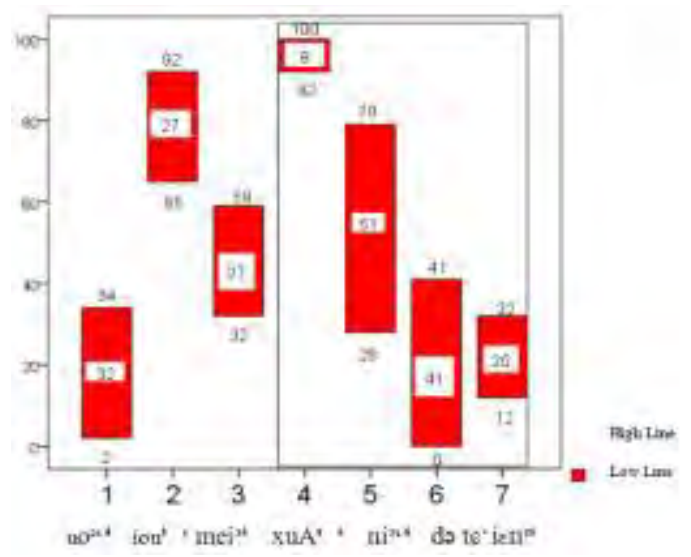

Figure 4. Li Xiao "yòu 1" sentence percentage chart 


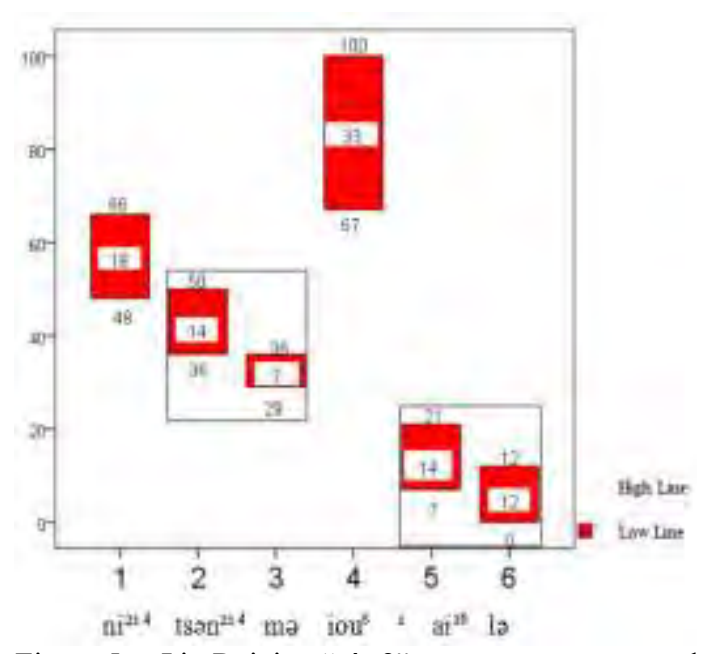

Figure 5. Liu Ruiping “yòu2" sentence percentage chart

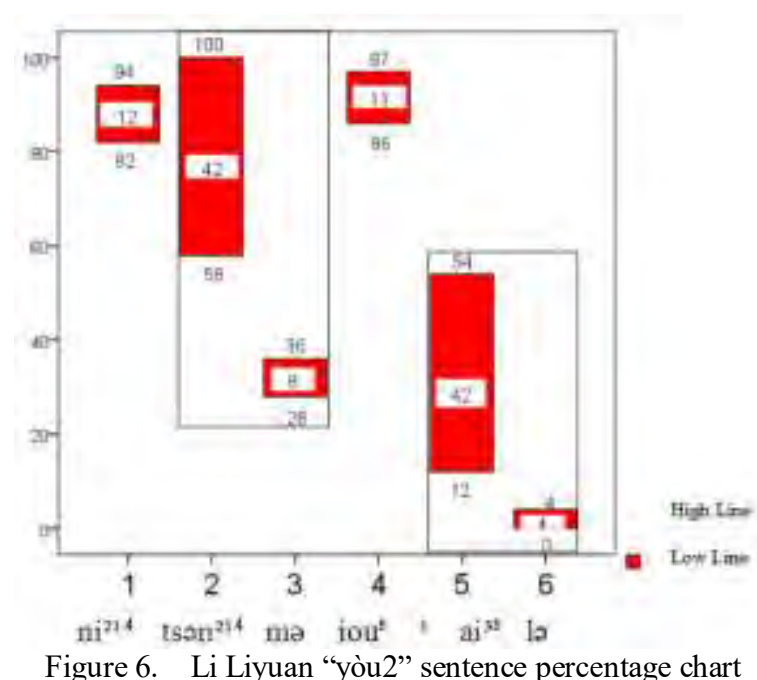

Figure 6. Li Liyuan "yòu2" sentence percentage chart

Lin Maocan (2011:11) pointed out that the broad focus is a declarative answer to "what happened". The focus area is the whole phrase. The accompanying accent is at the end of the phrase, called the wide focus accent, and the narrow focus is to do the problem. For a targeted answer, the focus field is consistent with the accompanying (narrow focus) accent position.[7]Xu Yi (1999) pointed out that the focal position of the focus position is extended, while the range of the position before the focus remains basically unchanged, and the position of the focus after the focus is compressed.[8]Lin Maocan (2011:13) concluded that the Chinese accent is mainly related to the pitch of the pitch. The heavier the voice, the larger the range is; the whole of the Yinping, the starting point of the deafness and the end of the Yangping. The turning point of the upper sound (relative to its front and rear syllables) is lower.[7]Lin Maocan (2015:41) also pointed out that the narrow focus accent falls on the Yinping, Yangping and Desonic Festivals and falls on the upper sound festival, and their acoustic performance is different.When falling in the Yinping, Yangping and Deming Festivals, the pitch height of the pitch curve is obviously raised, the range is enlarged, and the duration is often long (not always long); the pitch curve of the phrase is convex, and the syllable is before the peak. The scale is slowly rising, and the scale after the peak suddenly drops. [10]At present, the conclusions of the pitch performance of the focus accent are not completely consistent, but when the focus falls on the non-upper syllable, the treble line is the highest, and the subsequent syllables drop sharply; and the treble line of the focus expands upward to form a peak. The point of view is already a consensus. According to the above theory, the above percentage span map and the pitch delay rate of the corresponding syllable are combined. We think thetwo sentences "wǒ yòu méi huā nǐ de qián." "nǐ zěn me yòu lái le ?" are accented in two different ways. The following is an analysis of the stress of "wǒ yòu méi huā nǐ de qián." "nǐ zěn me yòu lái le ?"

Analysis of Focus in the Sentence "yòu1". In the negative sentence "wǒ yòu méi huā nǐ de qián" There are two forms of accent. The accent is the prosody word "yòu" and the rhythm phrase "huā nǐ de qián". When the accent of the whole sentence is "yòu", it is seen from Fig. 1 that the pitch point of the prosodic word "yòu"is the highest in the whole sentence, the span of the range is 26 , and the span of the range is the largest among all the syllables."yòu" is the accent of the whole sentence, and it also conforms to the law that the narrow focus accent falls on the non-upper syllable, forming a convex peak, and the scale after the peak suddenly dips. The "méi" pitch line in Figure 1 plummets and the range is greatly compressed.There are 6 cases similar to those in Figure 1. We used a percentage span to test whether the pitch of the syllables after the "re-s" of the seven subjects decreased, and Table 1 is listed. 
Table 1 Table of Comparing the Percentage Span of "wǒ yòu méi huā nǐ de qián."

\begin{tabular}{|c|c|c|c|c|c|c|c|c|c|c|c|c|}
\hline \multirow{2}{*}{$\begin{array}{l}\text { Difference } \\
\text { Subject }\end{array}$} & \multicolumn{2}{|c|}{ "wǒ"and "yòu" } & \multicolumn{2}{|c|}{$\begin{array}{l}\text { "yòu"and } \\
\text { "méi" }\end{array}$} & \multicolumn{2}{|c|}{$\begin{array}{l}\text { "méi" } \\
\text { and"huā" }\end{array}$} & \multicolumn{2}{|c|}{ "huā"and "nǐ" } & \multicolumn{2}{|c|}{ "nǐ " and "de" } & \multicolumn{2}{|c|}{$\begin{array}{l}\text { "de"and } \\
\text { "qián" }\end{array}$} \\
\hline & $\begin{array}{l}\text { High } \\
\text { Line }\end{array}$ & $\begin{array}{l}\text { Low } \\
\text { Line }\end{array}$ & $\begin{array}{l}\text { High } \\
\text { Line }\end{array}$ & $\begin{array}{l}\text { Low } \\
\text { Line }\end{array}$ & $\begin{array}{l}\text { High } \\
\text { Line }\end{array}$ & $\begin{array}{l}\text { Low } \\
\text { Line }\end{array}$ & $\begin{array}{l}\text { High } \\
\text { Line }\end{array}$ & $\begin{array}{l}\text { Low } \\
\text { Line }\end{array}$ & $\begin{array}{l}\text { High } \\
\text { Line }\end{array}$ & $\begin{array}{l}\text { Low } \\
\text { Line }\end{array}$ & $\begin{array}{l}\text { High } \\
\text { Line }\end{array}$ & $\begin{array}{l}\text { Low } \\
\text { Line }\end{array}$ \\
\hline Li Liyuan & -47 & -62 & 28 & 18 & 46 & 32 & 13 & 16 & -15 & -18 & 1 & -7 \\
\hline Yang Qianwei & -77 & -74 & 62 & 51 & -27 & -35 & 10 & 26 & 39 & 30 & -13 & -12 \\
\hline Liu Ruiping & -52 & -47 & 64 & 47 & -11 & -8 & 14 & 13 & 13 & 2 & 6 & -17 \\
\hline Ding Shaoyan & -51 & -24 & 43 & 13 & 5 & 13 & -7 & 39 & 39 & 43 & -6 & -20 \\
\hline Gao Ran & -32 & -12 & 41 & 22 & -11 & -14 & 51 & 24 & 24 & -3 & -14 & -9 \\
\hline Song Xin & -10 & 25 & 15 & -3 & 0 & -43 & 74 & 15 & 15 & -14 & -7 & 3 \\
\hline $\mathrm{Xu}$ Tongming & -49 & -42 & 19 & 21 & -5 & -19 & 70 & 5 & 5 & -5 & 26 & -5 \\
\hline
\end{tabular}

Note: Increase the "-" sign to increase and decrease to a positive number.

It can be seen from Table 1 that in the 7 cases where the accent is "yòu", the pitch line of "yòu" is rising except for the test Song Xin, and the upward trend is the largest in the sentence.In addition to the test on Song Xin, the pitch line after "yòu" is down, and the drop is also the maximum value of the whole sentence. The "yòu" forms a peak with the pitch of the preceding and succeeding words.From Table 1, we can calculate the average value of the "méi" pitch high line drop is about 38.86 percentage points, and the low line percentage drop average is 24.14 percentage points. The downtrend is the maximum in the whole tone field, and it is indeed down.

We use Shi Feng (2013: 191) to calculate the formula for the duration delay: $\mathrm{Dx}=(\mathrm{Sx}+\mathrm{Gx}) / \mathrm{S} \#$ [10](where Dx represents the stall rate of a syllable $\mathrm{x}$, and Sx represents the natural duration of the syllable $\mathrm{x}$ in the sentence, $\mathrm{S} \#$ represents the average length of the syllable in each sentence of the speaker, and Gx is the pause that occurs after each syllable. Since there is no pause after the syllable in the sentence, $\mathrm{Gx}$ is equal to 0 here.) The delay time of the pronunciation of the seven speakers is calculated, and the result is that the average duration of the "yòu" in the seven subjects is 1.2929. The average duration of the delay is 0.9230 , and the mean difference is 0.3699 ; We also performed a one-way analysis of variance on the percentage values of "yòu" and "méi" in the seven subjects. The $\mathrm{F}$ value was $7.634, \mathrm{p}=0.017<0.05$. Therefore, the percentage values of "yòu" and "méi" of the 7 subjects were significantly different, and our language analysis was statistically significant.

There are 3 examples of the stress of the whole sentence as "huā nǐ de qián". From Fig. 2 to Fig. 4 , it can be seen that the pitch line of the "huā nǐ de qián" rhythm is higher than other prosodic words, and the range span The range is $100,100,100$, and the span is the largest among all syllables. The average value of the four words "huā nǐ de qián" is $0.84,1.11,0.88$, and 1.14 , and two of the four syllables are greater than the average of the syllable length. In addition, the two near-syllables have a mean length, which is consistent with the focus accent.

Analysis of Focus in the Sentence "yòu2".In the rhetorical sentence "nǐ zěn me yòu lái le ?", there are two manifestations of accent. The accent is the prosodic word "yòu" and the prosodic word "zěn me". When the accent of the whole sentence is "yòu", it can be seen from Fig. 5 that the pitch point of the prosodic word "yòu" is the highest in the whole sentence, the span of the range is 33 , and the span of the range is the largest among all the syllables."yòu" is the accent of the whole sentence, which also conforms to the law that the narrow focus accent falls on the non-upper syllable, forming a convex peak, and the scale after the peak suddenly dips. The pitch line of "lái" in Fig. 5 dips and the range is greatly compressed. There are 8 cases similar to those in Fig. 6. Next, we use a percentage span table to test whether the syllables of the nine subjects after the "yòu" drops. 
Table 2 Table of Comparing the Percentage Span of "nǐ zěn me yòu lái le ?"

\begin{tabular}{|c|c|c|c|c|c|c|c|c|c|c|}
\hline \multirow{2}{*}{$\begin{array}{l}\text { Difference } \\
\text { Subject }\end{array}$} & \multicolumn{2}{|c|}{ "nǐ" and "zěn" } & \multicolumn{2}{|c|}{$\begin{array}{l}\text { "zěn" and } \\
\text { "me" }\end{array}$} & \multicolumn{2}{|c|}{$\begin{array}{l}\text { "me" and } \\
\text { "yòu" }\end{array}$} & \multicolumn{2}{|c|}{$\begin{array}{l}\text { "yòu" and } \\
\text { "lái" }\end{array}$} & \multicolumn{2}{|c|}{$\begin{array}{l}\text { "lái" and } \\
\text { "le" }\end{array}$} \\
\hline & $\begin{array}{l}\text { High } \\
\text { Line }\end{array}$ & $\begin{array}{l}\text { Low } \\
\text { Line }\end{array}$ & $\begin{array}{l}\text { High } \\
\text { Line }\end{array}$ & $\begin{array}{l}\text { Low } \\
\text { Line }\end{array}$ & $\begin{array}{l}\text { High } \\
\text { Line }\end{array}$ & $\begin{array}{l}\text { Low } \\
\text { Line }\end{array}$ & $\begin{array}{l}\text { High } \\
\text { Line }\end{array}$ & $\begin{array}{l}\text { Low } \\
\text { Line }\end{array}$ & $\begin{array}{l}\text { High } \\
\text { Line }\end{array}$ & $\begin{array}{l}\text { Low } \\
\text { Line }\end{array}$ \\
\hline Yang Qianwei & 19 & 31 & 35 & 18 & -84 & -81 & 81 & 74 & 0 & -3 \\
\hline Liu Ruiping & 16 & 12 & 14 & 7 & -64 & -38 & 79 & 60 & 0 & -7 \\
\hline Liu Rui & -6 & 5 & 26 & 12 & -55 & -36 & 32 & 43 & 57 & 27 \\
\hline Zhao Haiting & -3 & 7 & 43 & 20 & -57 & -19 & 97 & 59 & -10 & -12 \\
\hline Ding Shaoyan & 30 & 18 & 24 & 22 & -81 & -64 & 87 & 70 & 8 & 2 \\
\hline Gao Ran & 57 & 27 & -7 & 0 & -67 & -31 & 81 & 57 & 8 & -8 \\
\hline Li Xiao & -14 & -10 & 51 & 23 & -66 & -22 & 86 & 45 & 0 & -5 \\
\hline Song Xin & 63 & 32 & 15 & 4 & -75 & -38 & 63 & 44 & -25 & -40 \\
\hline $\begin{array}{l}\mathrm{Xu} \\
\text { Tongming }\end{array}$ & 14 & 0 & 25 & 19 & -44 & -5 & 91 & 55 & -6 & -2 \\
\hline
\end{tabular}

Note: Increase the "-" sign to increase and decrease to a positive number.

It can be seen from Table 2 that the accent line is "yòu", and the high and low lines are both rising, the maximum is 84 , the minimum is 5 , and the rising trend is the largest in the sentence. The pitch line of "lái" after "yòu", the high line and the low line are both reduced, the maximum value is 97 , the minimum value is 32 , and the drop is also the maximum value of the whole sentence. "yòu" forms a peak with the pitch of the front and back words.From Table 2, the average value of the "lái" pitch high line is 77.44 percentage points, and the low line percentage drop is 56.33 percentage points. The downward and downward trend is the maximum in the whole tone domain drop. We use Shi Feng (2013: 191) to calculate the formula of the duration delay rate: $D x=(S x+G x) / S \#[10]$, calculate the delay time of the pronunciation of the seven speakers, and get the result. In the case of 9 cases, The mean duration of the stop-loss rate is 1.5602, and the mean value of the "lái" duration is 1.1651 , with a mean difference of 0.3951 ; We performed a one-way analysis of variance on the percentage values of "yòu" and "lái" in 9 cases. The $F$ value was $7.375, p=0.015<0.05$, and the difference between the "yòu" and "lái" stall rates was significant, consistent with the stone. The conclusion of Feng (2013:200) also shows the characteristics of "yò" as the focus of the sentence from the difference in duration.

There is one example of the stress of the whole sentence as "zěn me". It can be seen from Figure 6 that the rhythm of the rhythm word "zěn me" is higher than other prosodic words, the span of the range is 72 , and the span of the range is in all syllables. The maximum, the word "zěn me"delay rate is 0.74 and 1.30, respectively, in line with the characteristics of focus accent.

Liu Yufeng (2002:24) believes that the focus is divided into static focus and dynamic focus. The dynamic focus is analyzed from the context. The position can be in various parts of the sentence, and the focus of the sentence will change with the needs of expression.[11]In the "yòu 1" sentence of the negative tone, the focus of "yòu" is to strengthen the negative tone and help the negative adverb "méi" to deny that I spend your money. The rhythm word "huā nǐ de qián" focuses on the "spend" action. In the "yòu" sentence of the rhetorical tone, the "yòu" focus is to emphasize the repetition of things and actions, and the "zěn me" focus is to emphasize the reasons. The emphasis on the two is different, so the focus is different. From this we can conclude that the tone adverb "yòu" can be used as a focus or not as a focus in the sentence.

Analysis of the difference between the focus of "yòu1" and "yòu2" sentences. What are the similarities and differences between "yòu1" and "yòu2" sentencesin the focus? " 1 " and " 2 " are in negation and rhetorical respectively. Chai Sen (1999: 65) believes that one of the basic meanings of "yòu" is the coexistence of two or more situations, and the emphasis of "yòu" in rhetorical questions. Nor did it completely leave the basic semantics that indicate the coexistence of two or more situations.[12]We also think that "nǐ zěn me yòu lái le ?" in the "yòu2"also contains the meaning of the repetition of the action, and the "yòu" in the "yòul"sentence has no such basic meaning. This mainly represents the incremental meaning of the negative and refutable subjective 
metaphor. Therefore, "yòu1" is more blurred than "yòu2". Through the above analysis, we can find "yòu2" with repetitive meaning, and it is more inclined to focus in the sentence. In 10 subjects, there are 9 cases where "yòu2" is used as the focus, which is more than "yòu1". It can be seen that the semantics of "yòu" expression have a certain influence on the focus of the work.

\section{Conclusion}

Through the above experiments, we can see that the modal Chinese adverb "yòu1" can focus on the whole sentence in both negative and rhetorical tone. "yòu1" expresses a negative tone and acts to strengthen the negative. When it is the focus, the treble line rises to the highest value of the whole sentence, forming a peak, and the pitch and high lines of the subsequent syllables are all lowered, and the tone field is greatly compressed. The length of "yòu1"is not the longest sentence, but its length exceeds the average of the whole sentence. The difference between the "yòu" and the subsequent first word is significantly different. "yòu2" expresses the rhetorical tone, and the "yòu" in the "yòu2" sentence contains the meaning of repeated action, so the repetition of the action that is more emphasized in "yòu2" is the focus. When "yòu2" is the focus, its treble line rises to the highest value of the whole sentence, forming a peak, and the pitch and high lines of the subsequent syllables are all lowered, and the syllable tonal domain is greatly compressed. However, the length of the "yòu" is the longest sentence of the whole sentence, and its sound length exceeds the average value of the whole sentence. The difference between the "yòu" and the length of the first word is significantly different, which is consistent with the typical speech performance of the narrow focus. "yòu1" is more ambiguous than "yòu2", and the tendency to focus is not as good as "yòu2".At the same time, we can also see that as a typical tone adverb, "yòu1" is often the focus, reread, which is inconsistent with previous research conclusions. Therefore, the study of the focus of language should be based on the analysis of experimental phonetics in order to get closer to the linguistic facts.

\section{Acknowledgements}

Fund Project: The National Social Science Fund Project "Study on the Semantic Structure and Pragmatic Functions of Chinese Function Words Based on Corpus and Chinese and Burmese, Vietnamese, and Thai Types”, item number: 13XYY027. E-mail: 810982089@qq.com.

\section{References}

[1] Shuxiang Lu . Eight hundred words in modern Chinese [M]. The Commercial Press. Updated version in January 1999.

[2] Halliday, Michael A.K. Notes on transitivity and theme in English[J]. Journal ofLinguistics, 1967,(3):199-244.

[3] Wang Li. Outline of Chinese Grammar [M]. Kaiming Bookstore in 1946. The first edition of the New Knowledge Press in October 1951.

[4] Shuxiang Lu . Chinese Miscellaneous Notes [M]. Shanghai: Shanghai Education Press, 1984: 104.

[5] Jinsheng Shi. The Refutation and Modalization of "again" and "also" and Its Grammaticalization [J].World Chinese Teaching,2005(4):52-60.

[6] Jun Li , Yin Shulin. The Usage of the Adverb “Again” [J]. Qiushi Journal, 2008(6):115-119.

[7] Maocan Lin.Chinese Focus Accent and Functional Tone and Its Characteristics[J].Chinese Character Culture,2011(6):10-23.

[8] $\mathrm{Yi} \mathrm{Xu}$, .Effects of tone and focus on the formation and alignment of $F_{0}$ contours.Journal of Phonetics .1999(27):55-105.

[9] Maocan Lin.The Similarities and Differences of Chinese and English Tune and the Teaching of Tone in Chinese as a Foreign Language__ I Cannot See the "Western Ocean Tune"[J].International Chinese Teaching Research,2015(3):40-46. 
[10] Feng Shi . Intonation Pattern—-The Cornerstone of Experimental Linguistics[M]. Beijing: The Commercial Press, 2013.

[11] Yufeng Liu . Chinese Focus and "De" Sentence[J].Chinese learning, 2201 (3): 24-30.

[12] Sen Chai . On the "again" and "also" that emphasizes the questioning [J]. World Chinese Teaching, 1999 (3): 65-69. 